\title{
Analysis of Helical Piles with Case Study in Medium Stiff Clay
}

\author{
R. Vijayalakshmi* \\ Department of Civil Engineering, Siva Subramania Nadar College of Engineering, Kalavakkam - 603110, \\ Tamil Nadu, India; vijayalakshmir@ssn.edu.in
}

\begin{abstract}
Objectives: To study about the design and the ultimate load capacity of helical piles, this depends on various parameters of helices. Methods/Analysis: This project focuses on analytical study of the response and behaviour of Helical Piles in the medium stiff clay. The parameters to be analysed are: Diameter of helical piles, outer diameter of hollow pile shaft and spacing between the adjacent helical plates. An optimal pile configuration was chosen and is then modelled using Helix Pile software based on the provided soil properties and its results are verified against the analysis results. Further, a case study was also done by comparing the capacities, scheduling and economic feasibility of Helical Piles and conventional concrete piles. Findings: From the analytical study it can be concluded that the increase in diameter of the helical plates has positive effect on the uplift capacity and compression behaviour; on the other hand the increase in the outer diameter of pile shaft has negative impact on the same. The spacing between the helices also increases the uplift capacity and compression behaviour of helical piles. Also Helical Piles are cost effective; require less in number and faster erecting when compared to concrete piles.
\end{abstract}

Keywords: Helical Piles, Helical Plates, Medium Stiff Clay

\section{Introduction}

Helical Piles (screw piles) are a valuable component in the geotechnical industry. Helical pile consists of a high strength circular/square shaped steel shaft to which one or more helix shaped bearing plates are attached (Figure 1). They are driven through the ground by twisting or 'torqueing' and the load carrying capacity of the pile is provided by helical plates and shafts by means of end bearing and skin friction respectively. Helical Piles can resist tensile loads as equally as compressive loads. Hence, some of the typical land structures for which this type of piles can be used are high rise buildings, chimney towers and transmission towers. In case of offshore structures, wave forces produce enormous tensile forces in the foundation system and hence Helical Piles are more suitable in such cases. Due to the ease of installation and versa- tility of helical piles, they are used worldwide in various construction industry and engineering fields; although in India, they are still a fairly new concept.

The behaviour of model screw piles in cohesive soils was studied in 1991 and reported. Screw piles, made out of hollow galvanized iron pipes, with variations in diameter of shaft, diameter of helical plates, number of helical plates and spacing between helical plates were screwed into soft to medium stiff clay.

It was concluded that decrease in moisture content leads to an increase in ultimate bearing capacity of piles and that the ratio of spacing of helical plates (s) to the diameter (d) of helical plates must be kept between 1-1.5 to obtain optimum capacity of piles $\underline{1}$. The behaviour of Helical Piles in cohesionless soil was reported in 2013. The uplift bearing capacities and compression behaviour

*Author for correspondence 
of Helical Piles were affected by the composition of helical plates and the area of the plates which are welded to the pile shaft. With the increasing in the embedment ratio $(\mathrm{D} / \mathrm{d})$ and helix diameter (d), compression and uplift loads increases ${ }^{2}$. The relationship connecting the axial capacities of Helical Piles with the installation torque was established for piles driven in cohesionless soils. The torsional resistance offered by the cohesionless soils during the helical pile installation was estimated and a theoretical model was developed for the same ${ }^{3}$. Review on different design methods of screw piles and the analysis technique was reported. The review mainly focuses on vertically loaded Helical Piles subjected to both compression load and tension loads. Review on both cohesive and cohesionless soils condition was reported ${ }^{4}$. The behaviour of Helical Piles in cohesionless soil (sand) was studied with the lateral loading condition. From the work it was concluded that the number of helices, spacing between the helices and the diameter of helix plate increases the lateral load carrying capacity of the pile in cohesionless soil. Due to the presence of helices the improvement ratio reached up to 2.83 at a displacement equal to $2.5 \%$ of the pile diameter $\underline{5}$.

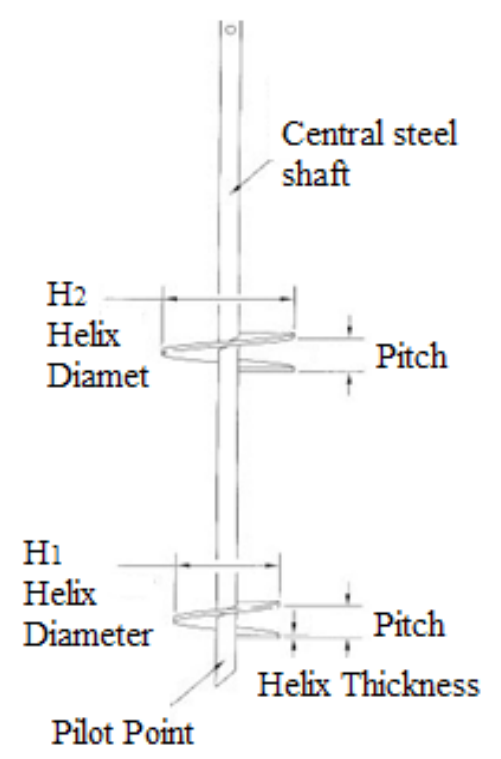

Figure 1. Illustration of helical pile.

The main scope of the work is to carry out analytical study to determine the ultimate capacity of helical Pile, by varying the parameters namely helix spacing and helix diameter. Theoretical calculations are done and the results are verified using HelixPile software. This work was finally concluded by conducting a case study on a medium stiff clay site located in Chembur, Mumbai, India, by comparing the ultimate strength, scheduling and economic viability of Helical Piles with square concrete piles.

\section{Methodology}

The helical pile load carrying capacity depends upon various parameters. From the literature review and previous work on helical piles, these parameters were identified and different values were chosen for analysis. The lengths of the helical pile were selected by an iterative process. A medium stiff clay site was identified for the analytical study and its soil properties were collected. Type of structure and the structural loads were also recognized for the case study. An excel sheet was developed based on theoretical formulas to find the structural behaviour and geotechnical capacity of the helical pile.

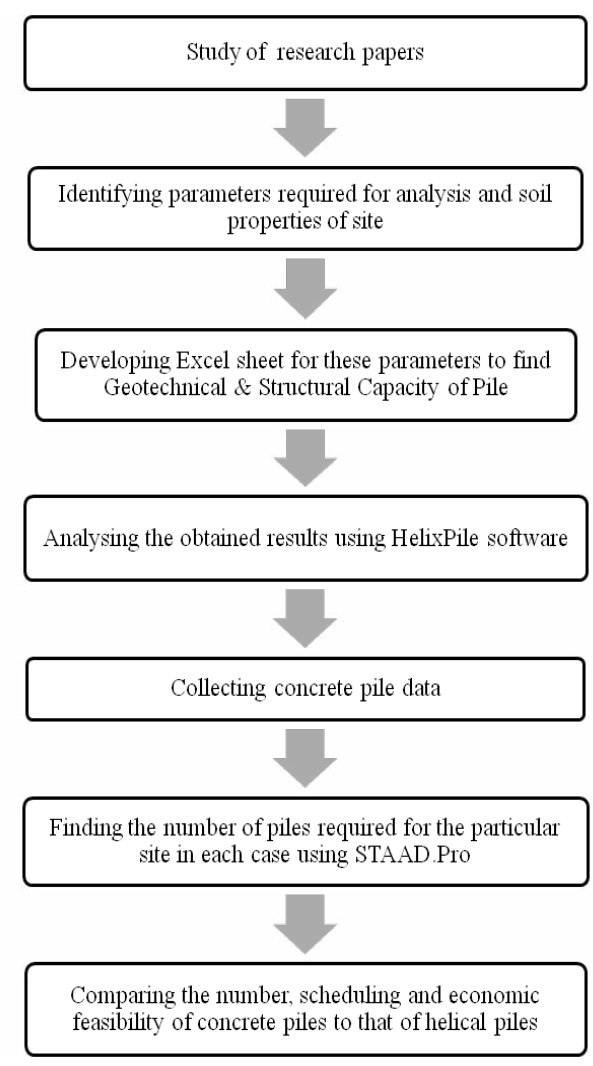

Figure 2. Methodology of the research work.

Properties of soil and pile data were given as input and the capacities were obtained. The geotechnical and 
structural capacities of all pile configurations using the different values of the parameters were obtained and a result table was formed. An optimal pile configuration was chosen from these values. The optimal pile configuration was analysed using HelixPile software. The Load vs. Settlement graph was plotted based on the given data and the safe load was determined. This load was verified against the capacity of our optimal pile configuration obtained from the analytical study.

For the case study, the suggested concrete pile data and the column load reactions in the foundation due to the structure were collected. The number of concrete piles required for our particular site area was found by an iterative process using STAAD. Pro, the capacity of all concrete piles are within the allowable stress limit. Same procedure was repeated to calculate the number of helical piles. The concrete piles were compared in terms of their number, scheduling and economic feasibility against our chosen helical pile configuration and the results were formed based on these findings. The flow chart showing the methodology carried out in this work is given in Figure 2.

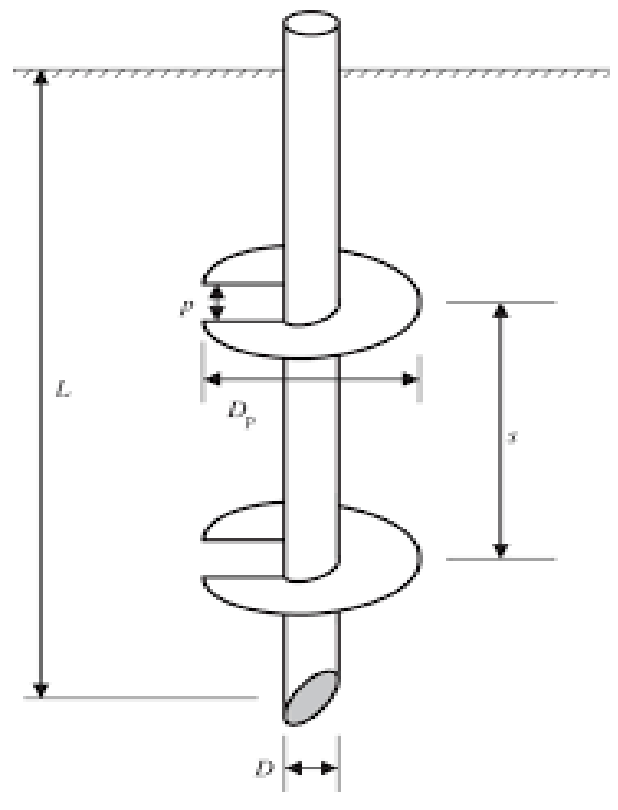

Figure 3. Pile configuration.

\section{Pile Data and Soil Parameters}

\subsection{Pile Configuration}

The end bearing capacity provided by central steel shaft (circular/square) and skin friction of the helix plate attached to the shaft are mainly responsible for the load carrying capacity of helical pile. The pile length was decided by first choosing an approximate length and calculating its bearing capacity and comparing that with the structural loads. This process is done iteratively till the optimum final length of the helical pile is found. Corrosion effects on the pile are neglected as galvanized sheet piles are used. Helices can be press-formed to a specified pitch or simply consist of flat plates welded at a specified pitch to the pile's shaft. Figure 3 shows the configuration of helical pile with various dimensional parameters. The shaft diameter adopted for analysis is $25.4 \mathrm{~cm}$ and $30.4 \mathrm{~cm}$. Diameters of helix plate used for the analysis were $0.6 \mathrm{~m}$, $0.8 \mathrm{~m}, 0.9 \mathrm{~m}, 1 \mathrm{~m}, 1.2 \mathrm{~m}$. The spacing of the helical plates is varied as 1, 1.5, 2 times of helix diameter.

\subsection{Soil Properties}

The SPT results are directly associated with settlement of foundations and bearing capacity. SPT counts are based on the number of blows and the $\mathrm{N}$ value. The soil properties found at the site located in Chembur, Mumbai are tabulated in Table 1.

Table 1. Soil properties at site

\begin{tabular}{|l|l|l|}
\hline S.No & Property & Value \\
\hline 1 & Soil type & Medium stiff clay \\
\hline 2 & Adhesion factor $(\alpha)$ & $2.4 \mathrm{KN} / \mathrm{m}^{2}$ \\
\hline 3 & Angle of Internal friction $(\varphi)$ & $32^{\circ}$ \\
\hline 4 & Cohesion of soil $(\mathrm{c})$ & $62.24 \mathrm{KN} / \mathrm{m}^{2}$ \\
\hline 5 & Depth of water table & $13 \mathrm{~m}$ \\
\hline 6 & Effective vertical stress $\left(\sigma_{\mathrm{v}}\right)$ & $8.3 \mathrm{KN} / \mathrm{m}^{2}$ \\
\hline 7 & Lateral earth pressure at rest $\left(\mathrm{K}_{\mathrm{o}}\right)$ & 0.3 \\
\hline 8 & Poisson s ratio $(\mathrm{v})$ & 0.35 \\
\hline 9 & SPT blow count $\left(\mathrm{N}_{70}\right)$ & $33.3 \mathrm{blows} / \mathrm{m}^{2}$ \\
\hline 10 & $\begin{array}{l}\text { SPT correlation factor }\left(\lambda_{\text {sPT }}\right) \\
\text { ( })\end{array}$ & $1.437\left(\mathrm{kN} / \mathrm{m}^{2}\right) /$ \\
\hline 11 & Unit weight of soil $\left(\gamma_{\mathrm{t}}\right)$ & $13.85 \mathrm{~m} / \mathrm{m}^{3}$ \\
\hline 12 & $\begin{array}{l}\text { Undrained shear strength of soil } \\
\left(\mathrm{s}_{\mathrm{u}}\right)\end{array}$ & $63.82 \mathrm{KN} / \mathrm{m}^{2}$ \\
\hline
\end{tabular}

\section{Analytical Study}

Analytical study was carried out to study the behaviour of Helical Piles by varying the helical diameter and the spacing between helices. An optimum pile section was chosen based on its ultimate bearing capacity found using cylindrical shear and Individual bearing methods. 


\subsection{Helical Pile Driving}

The helical pile is advanced into the soil with the help of a hydraulic torque motor by which it is rotated or "screwed" in to the soil. This type of installation minimises disturbance to the surrounding soil stratum. Installation energy is equal to the sum of energy required for soil penetration and energy loss due to friction. The installation energy is provided by the machine as Rotational energy also known as Installation Torque Downward forces also known as Crowd.

\subsection{Geotechnical Capacity}

During loading, the force applied for pile driving is transmitted to the surrounding soil. Thus, the strength of the soil is mainly responsible for the ultimate capacity of the pile. Soils derive their strength and ultimate load capacity from several characteristics like the internal friction angle $\varphi$, undrained shear strength of the soil, the adhesion factor $\alpha$, the volume weight $\gamma$. The allowable side shear and end bearing pressure of surrounded soil stratum is mainly responsible for the geotechnical capacity of helical pile.

\subsubsection{End Bearing Pressure of Helical Plate}

Three methods namely, SPT blow count correlation, unconfined compressive strength correlation, CPT cone tip resistance were used to determine the allowable side shear and end bearing pressure of the helical plate. The ultimate bearing capacity based on SPT blow count correlation is given by Equation 1. The ultimate bearing pressure and shear strength using unconfined compressive strength correlation is given by Equation 2 and Equation 3.

$$
\begin{array}{ll}
\mathrm{q}_{\mathrm{ult}}=12.5 \mathrm{~N}_{70} & \text { Equation } 1 . \\
\mathrm{q}_{\text {ult }}=9 \mathrm{~S}_{\mathrm{u}} & \text { Equation 2. } \\
\mathrm{S}_{\mathrm{u}}=0.5 \text { UCC } & \text { Equation 3. }
\end{array}
$$

Using the third method CPT cone tip resistance, the ultimate bearing pressure of fine-grain soils is given by Equation 4 and the side shear resistance is given by Equation 5.

$$
\begin{array}{ll}
\mathrm{q}_{\text {ult }}=11 \lambda_{\mathrm{SPT}} \mathrm{N}_{70} & \text { Equation 4 } \\
\mathrm{s}_{\mathrm{u}}=\mathrm{q}_{\mathrm{ult}} / 9 & \text { Equation 5 }
\end{array}
$$

Allowable bearing capacity in compression is given by Equation 6.

$$
\mathrm{q}_{\mathrm{a}}=\mathrm{q}_{\mathrm{ult}} / \Omega \quad \text { Equation } 6 .
$$

\subsubsection{Bearing Capacity of Helical Pile}

Individual bearing method and cylindrical shear method are the two theoretical methods in soil mechanics to determine the bearing capacity of helical piles. The spacing where the two methods converge varies with soil density, strength, consistency, diameter of the helical pile as well as groundwater conditions, depth below ground.

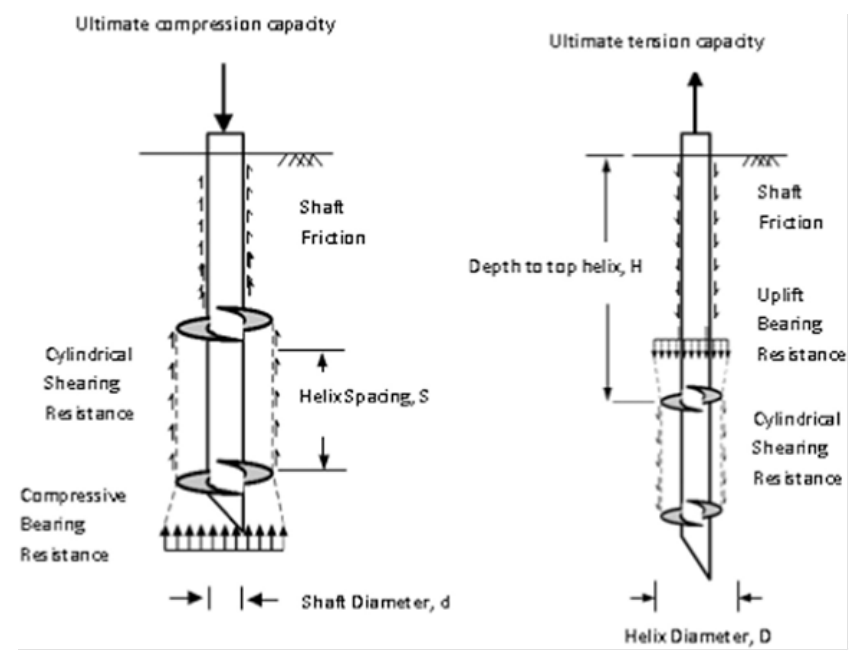

Figure 4. Cylindrical shear effect $\stackrel{4}{\text {. }}$
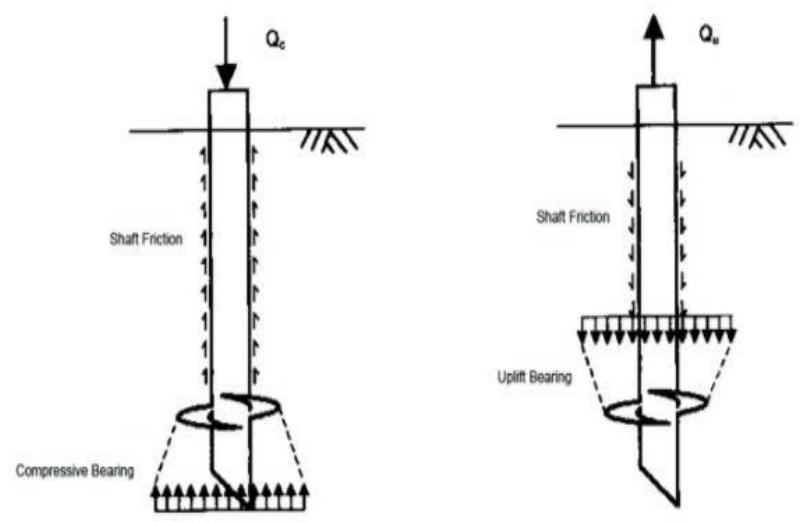

Figure 5. Individual bearing effect ${ }^{4}$.

When the spacing between helical bearing plates is less a cylindrical shaped shear failure surface is formed between the two adjacent helical plates. The bearing capacity of the helical pile in Cylindrical Shear method is the combination of end bearing of the bottom helical plate and side shear of the cylinder of soil encased between the helical bearing plates. This effect is called as "cylindrical 
shear" effect. The entire volume of soil between the helical bearing plates is assumed to be mobilized in cylindrical shear method. The ultimate bearing capacity of a helical pile based on the cylindrical shear method is given by Equation 7. The illustration of cylindrical shear method is shown in Figure 4.

$$
\mathrm{P}_{\mathrm{u}}=\mathrm{q}_{\mathrm{a}} \mathrm{A}_{\mathrm{n} 1}+\mathrm{s}_{\mathrm{u} \pi} \mathrm{DB}+\pi \mathrm{dLa} \quad \text { Equation } 7 .
$$

When the spacing between the helical plates is large enough, each helical plate behaves independent of others this is called as individual bearing method. In this method the individual capacities of all the helical bearing plates are summed up to calculate the bearing capacity of the helical pile. This is called the "individual bearing" effect. The ultimate bearing capacity of the helical pile based on Individual Bearing method given by Equation 8 . The illustration of individual bearing method is shown in Figure 5.

$$
\mathrm{Pu}=\sum(\mathrm{qa} * \mathrm{An})+\pi \mathrm{dLa} \quad \text { Equation } 8 .
$$

The least of the values calculated from above two methods is taken as the final allowable bearing capacity of the pile.

\subsection{Installation Torque and Bearing Capacity Relation}

The tensile capacity of the pile depends upon the torsional resistance which occurs during the helical pile penetration. Equation 9 gives the relation connecting the ultimate axial capacity and installation torque.

$$
\mathrm{Q}_{\mathrm{t}=\mathrm{KT} \mathrm{T}^{*} \mathrm{~T}} \quad \text { Equation } 9 .
$$

\subsection{Structural Capacity}

The overall structural capacity of a helical anchor is sum of capacity of central shaft and helix plate. The structural capacity of the helical pile is determined based on AISC LRFD code as follows (Equations 10-14).

$$
\mathrm{P}_{\mathrm{n}}=\mathrm{A}_{\mathrm{g}} \mathrm{F}_{\mathrm{cr}}
$$

Equation 10.

$\mathrm{F}_{\text {cr }}$ is the Critical buckling stress $\left(\mathrm{kN} / \mathrm{mm}^{2}\right)$ which depends on the slenderness ratio $\lambda$ in the following way:

If $\lambda>1.5$, Critical Stress

$\mathrm{F}_{\mathrm{cr}}=\left(0.877 / \lambda^{2}\right)^{\star} \mathrm{F}_{\mathrm{y}} \quad$ Equation 11. If $\lambda \leq 1.5$, Critical Stress

$$
\begin{array}{lr}
\mathrm{F}_{\mathrm{cr}}=\left(0.65^{\star} \lambda^{2}\right)^{*} \mathrm{~F}_{\mathrm{y}} & \text { Equation } 12 . \\
\lambda=\left((\mathrm{kL} / \mathrm{r} \pi)^{*}(\sqrt{ }(\mathrm{F} / \mathrm{F}))\right. & \text { Equation } 13 .
\end{array}
$$$$
\text { Allowable strength, Pallow }=\mathrm{Pn} / \Omega \text { Equation } 14 \text {. }
$$

Using the above mentioned methods, the Structural and geotechnical capacity of the helical pile were calculated using MS Excel and tabulated in Table 1.

\section{Numerical Modelling}

Numerical modelling of these Helical Piles was carried out using HelixPile software. Different variety of stage conditions and unlimited number of soil profiles can be included in the software. Latest codal recommendations are included in the helix pile software which helps to analyse various failure modes of helical piles.

\subsection{Numerical Modelling Parameters}

Based on the tension and compression loads arrived from the design, HelixPile software optimizes the length of the pile. In other ways the pile length can be manually edited if the values are known. The torsional pile capacity, tensile shaft capacity are calculated automatically from the given shaft dimension data. The helical pile geotechnical capacity was estimated from the torque rating and the torque installation factor. The maximum compression and tension load are to be defined for analysis.

Our Chosen pile configuration has a shaft diameter of $25.4 \mathrm{~cm}$ and a thickness of $1.3 \mathrm{~cm}$. Two numbers of helical plates with diameter of $90 \mathrm{~cm}$, thickness of $1.59 \mathrm{~cm}, 15.24$ $\mathrm{cm}$ pitch and $1.35 \mathrm{~m}$ spacing between the helical plates were used.

Some common types of soil medium with its specified properties are available by default in the software. The required soil medium can be generated manually by editing properties like cohesion, unit weight, shear strength angle of internal friction etc. Standard Penetration Test (SPT) values for various depths along with the in-situ stresses developed in the specimen are specified for the settlement analysis. Cone penetrometer values like cone tip resistance, shaft resistance are also needed as the method followed for analysis is the CPT cone tip resistance method. The soil properties mentioned in section Table 2 were entered in the required fields. Cone penetrometer data values $\mathrm{Q}_{\text {shaft }}$ and $\mathrm{Q}_{\text {tip }}$ are $2.4 \mathrm{kPa}$ and 249.8 $\mathrm{kPa}$ respectively. Since galvanized steel shafts are used, effects of corrosion are neglected. The analysis is based on AISC ASD code. Factor of safety is taken as 2 and Meyerhof bearing factors have been used. The helical pile type can be selected directly from the given different options. We have chosen pipe type shaft For P-Y analy- 
sis, load is applied in increments on the pile section and the corresponding Load vs. Settlement graph is plotted. For $12 \mathrm{~mm}$ settlement, the value of ultimate load is 835 $\mathrm{kN}$. The corresponding safe load is $417 \mathrm{KN}$ by applying a factor of safety of 2 . This is in range with our analytical capacity. Pile type and pile data used in helix software is shown as screen shot in Figures 6 and 7 respectively. The desired pile section is analyzed by the software and the results are generated for both compression and tension in cylindrical shear and individual bearing methods. The Load vs. Settlement graph was plotted (Figure 8). The layout of Helical Piles is shown in Figure 9 and the layout of concrete piles is shown in Figure 10.

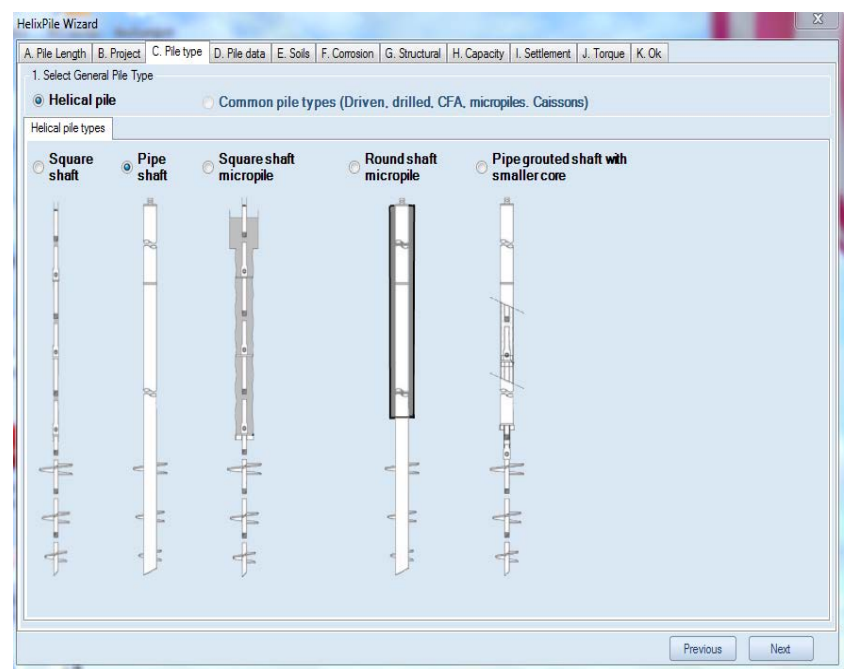

Figure 6. Pile shaft type.

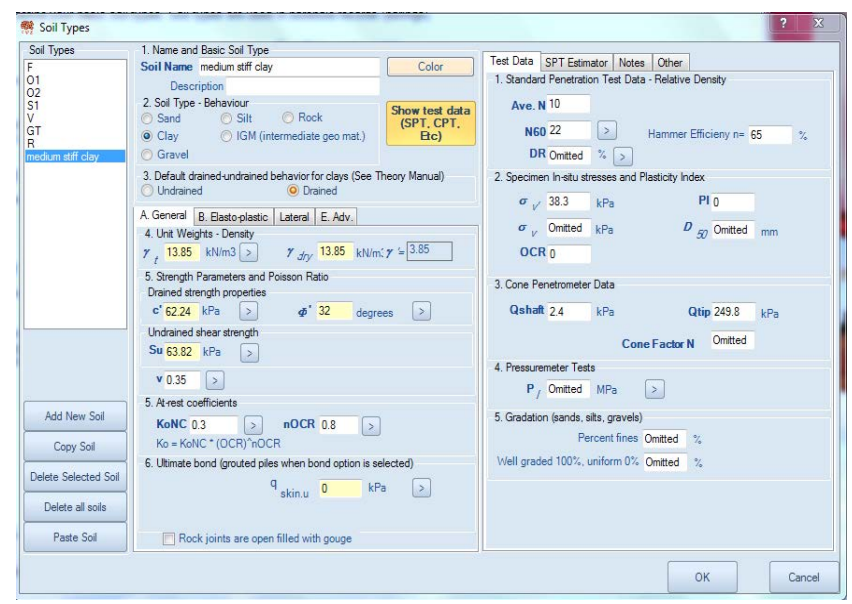

Figure 7. Pile data.

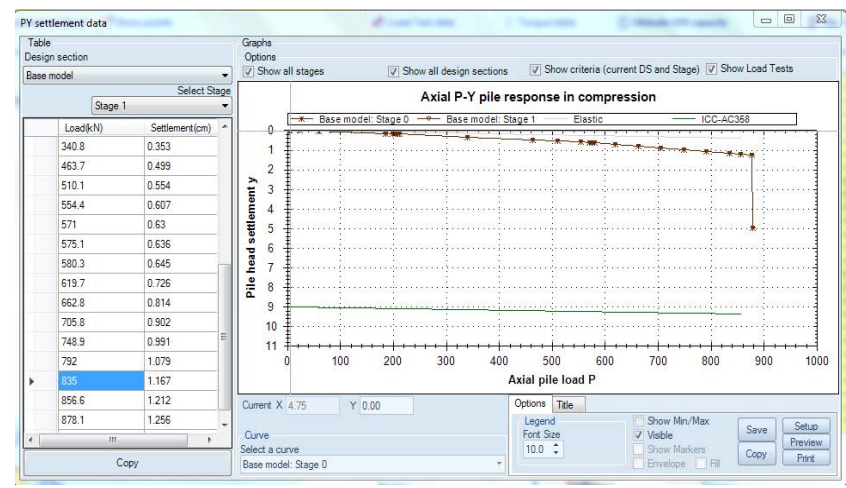

Figure 8. Load vs. Settlement graph.

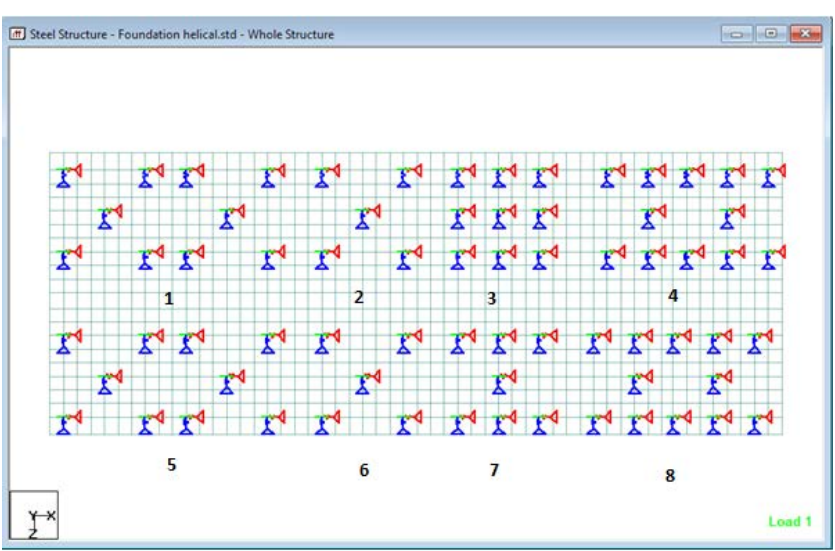

Figure 9. Layout of helical piles.

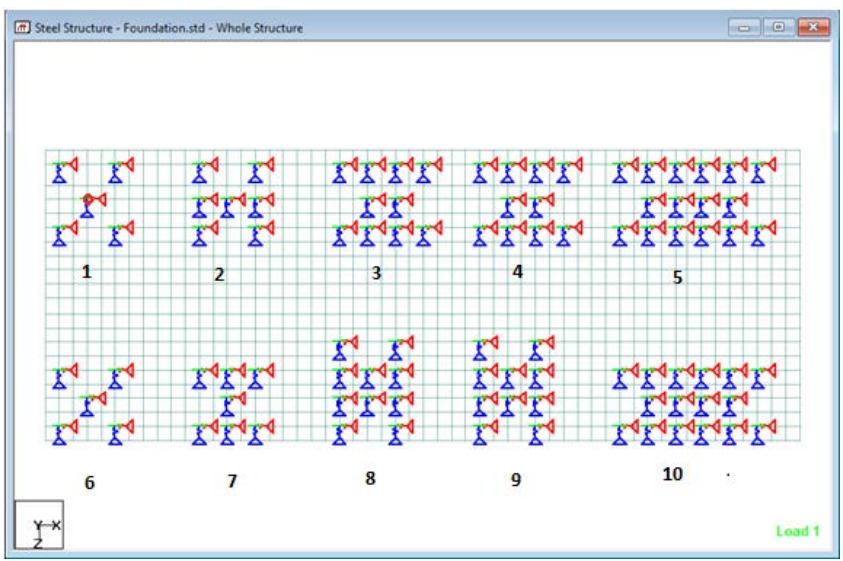

Figure 10. Layout of concrete piles.

\section{Case Study}

The medium stiff clay site chosen for case study is located in Chembur, Mumbai, India. It is centred in Trombay 

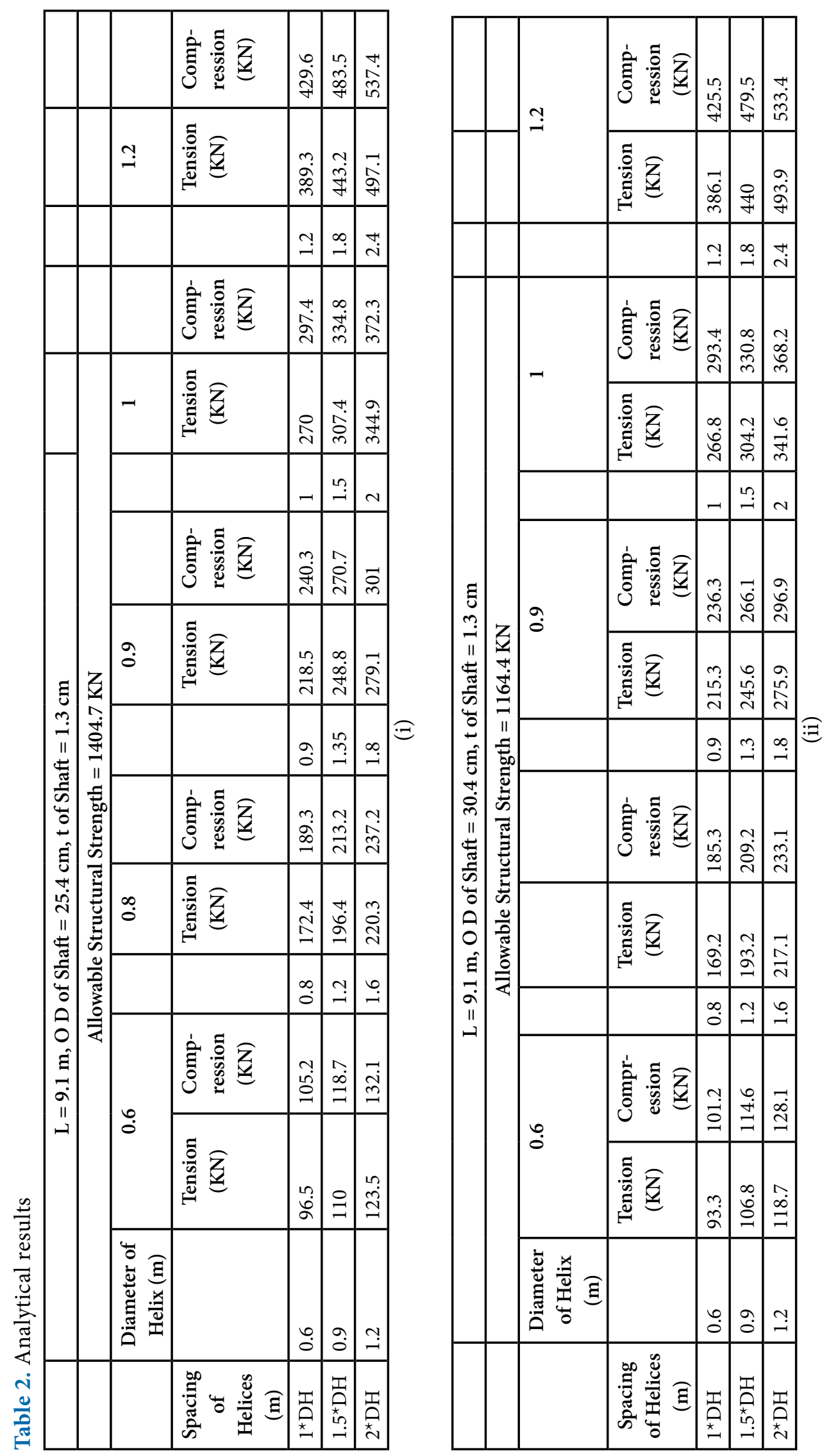
Industrial Area. It is a hybrid industrial structure with concrete columns up to $10 \mathrm{~m}$ and then steel columns for about $20 \mathrm{~m}$. The total area of the structure is 413 sq.m. The soil properties of the site are listed in Table 2.

\subsection{Concrete Pile Configuration}

The suggested pile configuration for the chosen site was a driven square concrete pile each of Length $9.1 \mathrm{~m}$, Dimension $0.4 \mathrm{~m}$ and Capacity $180 \mathrm{kN}$. This pile is compared against our chosen helical pile configuration of Length $9.1 \mathrm{~m}$, O.D of shaft $25.4 \mathrm{~cm}$, helix diameter $0.9 \mathrm{~m}$, helical spacing $1.35 \mathrm{~m}$ and capacity $270.7 \mathrm{kN}$ in, Number of piles, Scheduling, Economic Viability.

\subsection{Column Loads}

The entire structural area is provided with a single pile cap .This is generated in STAAD.Pro and Finite Element Analysis is performed. The coordinates and the support reactions of the column nodes have been provided as per Table 3 and they were assigned to the meshed model as Nodal loads.

\subsection{Number of Piles}

For the chosen structural area, the optimum number of piles required in case of concrete pile and in case of helical pile is determined based on iterative analysis using STAAD.Pro.

The pile nodes are assigned with "Fixed But Support". The Fixed But support condition is used to mimic the stiffness conditions offered due to pile-soil interaction for pile analysis.

\subsubsection{Concrete Piles}

- For concrete piles, the stiffness coefficients of the Fixed But Support are assigned as follows:

- $\mathrm{KFX}-7005.06 \mathrm{kN} / \mathrm{m}$.

- $\mathrm{KFY}-28020.2 \mathrm{kN} / \mathrm{m}$.

- $\mathrm{KFZ}-7005.06 \mathrm{kN} / \mathrm{m}$.

An iterative analysis to find the number of piles is done such that the Max $\mathrm{F}_{\mathrm{y}}$ for all the pile nodes does not exceed the allowable concrete pile capacity of $180 \mathrm{kN}$. Hence, the optimum number of concrete piles was found to be 96 .

\subsubsection{Helical Piles}

- For helical piles, the stiffness coefficients of the Fixed But Support are assigned as follows:

- $\mathrm{KFX}-8756.5 \mathrm{kN} / \mathrm{m}$.

- $\mathrm{KFY}-45533.8 \mathrm{kN} / \mathrm{m}$.

- $\mathrm{KFZ}-8756.5 \mathrm{kN} / \mathrm{m}$.

The same procedure as above is followed such that the Max Fy for all the pile nodes does not exceed the allowable helical pile capacity of $270.7 \mathrm{kN}$ as given in Table 3 . Hence, the optimum number of Helical Piles arrived was 70 .

\subsection{Scheduling}

With the availability of construction personnel, equipment and suitable weather condition, in a day approximately, 10

Table 3. Column node reactions

\begin{tabular}{|l|l|l|l|l|l|l|}
\hline & Horizontal & Vertical & Horizontal & Moments & & \\
\hline Node & $\mathrm{F}_{\mathrm{X}} \mathrm{KN}$ & $\mathrm{F}_{\mathrm{X}} \mathrm{KN}$ & $\mathrm{F}_{\mathrm{X}} \mathrm{KN}$ & $\mathrm{M}_{\mathrm{X}} \mathrm{KN}-\mathrm{m}$ & $\begin{array}{l}\mathrm{M}_{\mathrm{Y}} \\
\mathrm{KN}-\mathrm{m}\end{array}$ & $\begin{array}{l}\mathrm{M}_{\mathrm{Z}} \\
\mathrm{KN}-\mathrm{m}\end{array}$ \\
\hline 1617 & -2.41 & -1.324 .03 & -12.58 & -27.44 & 0.00 & 5.67 \\
\hline 1628 & -6.52 & -1.293 .38 & 17.98 & 33.88 & 0.00 & 12.99 \\
\hline 1707 & 2.37 & -1.343 .85 & -12.77 & -27.84 & 0.00 & -4.63 \\
\hline 1718 & 6.56 & -1292.17 & 18.35 & 34.58 & 0.00 & -12.46 \\
\hline 1851 & 0.17 & -1822.96 & -6.16 & -9.42 & 0.00 & 1.26 \\
\hline 1862 & -0.19 & -1567.44 & 7.34 & 18.30 & 0.00 & 1.55 \\
\hline 1995 & -1.79 & -1503.04 & -5.59 & -5.50 & 0.00 & 5.86 \\
\hline 2006 & -1.57 & -1300.71 & 7.67 & 21.75 & 0.00 & 4.98 \\
\hline 2139 & -5.57 & -1166.94 & -9.97 & -12.95 & 0.00 & 14.25 \\
\hline 2150 & -6.55 & -1166.54 & 5.37 & 17.56 & 0.00 & 15.59 \\
\hline 2283 & -5.98 & -664.89 & -8.01 & -7.60 & 0.00 & 17.08 \\
\hline
\end{tabular}


concrete piles can be erected. While in the case of Helical Piles it is 30 piles a day. So, for the erection of 96 concrete piles it takes around 10 days, for the erection of 70 Helical Piles it takes around 3 days. Hence, a week's time can be saved when Helical Piles are used.

\subsection{Economic Viability}

On comparing the entire cost of one concrete and helical pile, it is estimated approximately as Rs. 1,95,000 for concrete pile and Rs. 1,30,000 for helical pile. This overall cost is inclusive of Cost of materials, Cost of manufacturing the pile, Cost of equipment required for erection. Hence, for 96 concrete piles it costs around Rs. 1,87,20,000. For 70 Helical Piles it costs Rs. 91,25,000. Hence around Rs. $50,70,000$ would be the estimated amount saved when Helical Piles are used instead of concrete piles.

\section{Results}

Based on the analytical calculation and numerical modelling following results were obtained:

- Diameter of pile shaft has negative effect on pile capacity, as the diameter of the pile shaft increases, the capacity of the helical pile decreases. (Since we have a constant helical plate diameter, an increase in pile shaft diameter would lead to a decrease in the helical plate area and therefore the resistance offered by the plates is reduced).

- The capacity of the helical pile increases with the increase in spacing between the helical plates and increase in diameter of helix.

- The extent to which the above effect lasts is not covered by our project scope and hence requires further studies and experimental investigations to concur.

- By taking into account the soil properties of the site, the optimal helical pile configuration with Length $=9.1 \mathrm{~m}, \mathrm{O} . \mathrm{D}$ of shaft $=25.4 \mathrm{~cm}$, Diameter of helix $=0.9 \mathrm{~m}$ and spacing between the helices $=1.35 \mathrm{~m}$ is chosen. The ultimate capacity and allowable capacity of this chosen configuration are $270.7 \mathrm{kN}$ and $406 \mathrm{kN}$ respectively.

$\bullet$

- The chosen pile configuration was modelled using HelixPile software. The Load vs. Settlement graph was plotted using incremental loads. For maximum allowable settlement of $12 \mathrm{~mm}$, the value of ultimate load is $835 \mathrm{kN}$. The corresponding safe load is $417 \mathrm{KN}$ by applying a factor of safety of 2 .

-

- The load obtained from helix pile software was verified against the pile capacity obtained from the analytical study and the value was found to be within the range.

-

- A case study was conducted in a medium stiff clay site located in Chembur, Mumbai for an area of 413 sq.m. The suggested driven square concrete pile configuration of length $9.1 \mathrm{~m}$ and side dimension $0.9 \mathrm{~m}$ was compared against our chosen helical pile configuration in number, scheduling and economic viability.

- The number piles in each case were found by an iterative analysis using STAAD.Pro. For our chosen area, when concrete piles are used 96 nos. are required and when Helical Piles are used only 70 nos. are required. Hence 26 lesser piles are required when Helical Piles are used.

- The 96 concrete piles require 10 days for their erection while the 70 Helical Piles require only 3 days for their erection. Hence a week's time can be saved when Helical Piles are used.

- The overall cost of the Helical Piles is Rs. $91,25,000$ and the cost of concrete piles is Rs. $1,87,20,000$. Hence Rs. 50,70,000 would be the estimated amount saved when Helical Piles are used instead of concrete piles.

- Furthermore, concrete piles require removal of debris, cause noise pollution, are not eco-friendly and are not suitable for all weather conditions. These problems can be avoided when Helical Piles are used.

\section{Conclusion}

The position of helices in the pile shaft and the area of the helical plates affect the compression and the uplift capacity of helical piles. The tensile capacity of the Helical Piles is as good as their compressive capacity. The overall cost of the Helical Piles is less when compared to the conventional concrete piles.

As its bearing capacity is higher than the concrete piles, less number of Helical Piles is needed for a selected 
area. They can be screwed in at a faster rate with less equipment requirement and do not require any excavation.

\section{References}

1. Narasimha Rao S, Prasad YVSN, Dinakara Shetty M. The behaviour of model screw piles in cohesive soils. Soils and Foundations. 1991; 31(12):35-50.

2. Abdel-Rahim HHA, Taha YK, Sharif Mohamed WEDE. The compression and uplift bearing capacities of Helical Piles in cohesionless soil. Journal of Engineering Science. 2013; 41(6):2055-64.

3. Sakr M. Relationship between installation torque and axial capacities of Helical Piles in cohesionless soils. Canadian Geotechnical Journal. 2015; 52(6):747-59. https://doi. org/10.1139/cgj-2013-0395

4. Mohajerani A, Bosnjak D, Bromwich D. Analysis and design methods of screw piles: A review. Soils and Foundations. 2016; 56(1):115-28. https://doi.org/10.1016/j. sandf.2016.01.009

5. Abdrabbo FM, El Wakil AAZ. Laterally loaded Helical Piles in sand. Alexandria Engineering Journal. 2016; 55(4):323945. https://doi.org/10.1016/j.aej.2016.08.020

Nomenclature

\begin{tabular}{|l|l|}
\hline$L$ & Length of the pile \\
\hline$D$ & Outer diameter of the shaft \\
\hline$D_{p}$ & Diameter of the helix \\
\hline
\end{tabular}

\begin{tabular}{|l|l|}
\hline $\mathrm{P}$ & Pitch of the helix \\
\hline $\mathrm{S}$ & Spacing between the helix \\
\hline $\mathrm{S}_{\mathrm{u}}$ & Undrained shear strength $\left(\mathrm{kN} / \mathrm{m}^{2}\right)$ \\
\hline $\mathrm{UCC}$ & Unconfined compressive strength $\left(\mathrm{kN} / \mathrm{m}^{2}\right)$ \\
\hline $\mathrm{q}_{\mathrm{ult}}$ & Ultimate bearing pressure $\left(\mathrm{kN} / \mathrm{m}^{2}\right)$ \\
\hline $\mathrm{N}_{70}$ & SPT blow count at an energy ratio of 70 \\
\hline$\lambda_{\text {SPT }}$ & SPT correlation factor \\
\hline$\Omega$ & Factor of safety \\
\hline $\mathrm{CPT}$ & Cone tip resistance capacity in tension \\
\hline $\mathrm{q}_{\mathrm{a}}$ & 0.87 $\mathrm{q}_{\mathrm{ult}}$ \\
\hline $\mathrm{q}_{\mathrm{a}}$ & Allowable bearing capacity $\left(\mathrm{kN} / \mathrm{m}^{2}\right)$ \\
\hline$A_{n 1}$ & Area of the bottom helix $\left(\mathrm{m}^{2}\right)$ \\
\hline $\mathrm{B}$ & spacing between helical plates $(\mathrm{m})$ \\
\hline $\mathrm{A}_{\mathrm{n}}$ & Area of the nth helical bearing plate $\left(\mathrm{m}^{2}\right)$ \\
\hline$\alpha$ & Adhesion between the soil and the shaft $\left(\mathrm{kN} / \mathrm{m}^{2}\right)$ \\
\hline $\mathrm{A}_{\mathrm{g}}$ & Gross cross-sectional area of the pile shaft $\left(\mathrm{mm}^{2}\right)$ \\
\hline $\mathrm{Q}_{\mathrm{t}}$ & Ultimate axial capacity $(\mathrm{kN})$ \\
\hline $\mathrm{K}_{\mathrm{T}}$ & Empirical torque factor $\left(\mathrm{m}^{-1}\right)$ \\
\hline $\mathrm{T}$ & Average installation torque $(\mathrm{kNm})$ \\
\hline $\mathrm{P}_{\mathrm{n}}$ & Nominal capacity $(\mathrm{kN})$ \\
\hline $\mathrm{F}_{\mathrm{v}}$ & Minimum yield of shaft $\left(\mathrm{kN} / \mathrm{mm}{ }^{2}\right)$ \\
\hline $\mathrm{F}_{\mathrm{cr}}$ & Critical buckling stress \\
\hline $\mathrm{k}$ & Effective length factor \\
\hline $\mathrm{r}$ & Radius of gyration $(\mathrm{m})$ \\
\hline $\mathrm{E}$ & modulus of elasticity $\left(\mathrm{kN} / \mathrm{mm}{ }^{2}\right)$ \\
\hline
\end{tabular}

